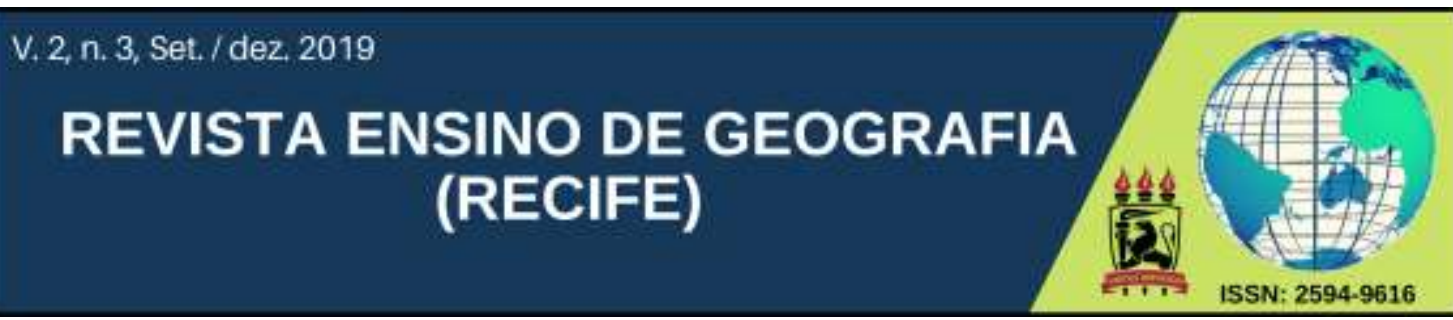

\title{
A IMAGEM COMO RECURSO DIDÁTICO PARA O ENSINO DE GEOGRAFIA NA EDUCAÇÃO BÁSICA
}

\author{
Jean Oliveira Campos \\ Professor substituto da rede municipal de ensino de Esperança-PB \\ jeannolliveira@gmail.com \\ Nathália Rocha Morais \\ Professora substituta do Departamento de Geografia da UEPB \\ nathalia_rochamorais@hotmail.com
}

Artigo recebido em 20/11/2019 e aceito em 22/12/2019

\begin{abstract}
RESUMO
Diante da necessidade de retirar o ensino de Geografia do campo da abstração atribuída por grande parte dos alunos, os recursos didáticos emergem no contexto do processo de ensino-aprendizagem desta disciplina como grandes facilitadores da abordagem dos conteúdos geográficos. Dentre os principais recursos didáticos utilizados no espaço escolar está a imagem, pois esta fornece um leque de possibilidades que podem ser exploradas com vistas a conferir maior significação na construção do conhecimento geográfico. Diante do exposto, este trabalho tem como objetivo apresentar a experiência vivenciada durante a realização do Estágio Supervisionado II do curso de Licenciatura em Geografia da Universidade Estadual da Paraíba, na qual foi realizada uma abordagem utilizando a imagem como recurso didático. Para tanto, foi feita a identificação dos principais anseios dos alunos em relação à disciplina e a execução de um plano de intervenção considerando as principais dificuldades apontadas. $\mathrm{O}$ entendimento das dificuldades foi de grande importância, pois permitiu repensar as metodologias visando tornar as aulas mais dinâmicas e atrativas. A regência foi desenvolvida em uma turma de Ensino Fundamental II de uma escola pública da cidade de Esperança-PB, e durante o período buscou-se a construção de um conhecimento significativo e próximo da realidade dos alunos. Como resultados da abordagem dos conteúdos através de imagens podemos destacar o crescente interesse pela disciplina, acrescido da participação e dos grandes avanços na compreensão dos conteúdos propostos, o que evidenciou a constante necessidade de reavaliar as práticas desenvolvidas com fins a um aprendizado menos abstrato e mais prazeroso.
\end{abstract}

Palavras-chave: Geografia Escolar; Estágio Supervisionado; Recurso Didático; Imagem. 


\title{
IMAGE AS A DIDACTIC RESOURCE FOR THE EDUCATION OF GEOGRAPHY IN BASIC EDUCATION
}

\begin{abstract}
In front of the need to remove the teaching of Geography from the field of abstraction attributed by most students, the didactic resources emerge in the teaching-learning process context of this discipline as being great facilitators of the geographic contents approach. Among the image being the main didactic resources used in the educational space, it's because it provides a range of possibilities that can be explored in order to give greater significance in the geographic knowledge construction. Given the above, this paper aims to present the experience lived during the II Supervised Internship realization from the Geography Majoring Degree at Universidade Estadual da Paraíba, which was made an approach using the image as a didactic resource. To this end, were identified the main desires of the students about the subject and the execution of an intervention plan considering the main difficulties pointed. Understanding the difficulties was of great importance because it allowed rethinking the methodologies aiming to make the classes more dynamic and attractive. Was developed the regency in an II Elementary School class of a public school in the city of Esperança-PB and during the period was sought to build significant knowledge and close to the students' reality. As a result of the approach of content through images, we can highlight the discipline growing interest, increase participation and greater advances in understanding the proposed content, what has evidenced the constant need to reevaluate the developed practices aiming for less abstract and more pleasurable learning.
\end{abstract}

Key words: Schooling Geography; Supervised Internship; Didactic Resource; Image.

\section{INTRODUÇÃO}

No ensino de Geografia na atualidade algumas metodologias ainda encontram-se alicerçadas sobre práticas tradicionais a partir das quais docentes apenas reproduzem conhecimentos e informações, sem preocupação alguma com a construção de um conhecimento concreto e significativo para o aluno.

O modelo tradicional de ensino, apesar de muito questionado pelas novas perspectivas educacionais, ainda mostra fortes resquícios nos diversos espaços escolares, seja por meio de reprodução mnemônica dos conteúdos ou mesmo pela priorização do ensino em detrimento da aprendizagem evidenciando um cenário de práticas cristalizadas que necessitam ser repensadas pelos profissionais da educação. No âmbito da Geografia tais práticas acabam por tornar as aulas cansativas, enfadonhas e vistas como desprovidas de importância para a formação cidadã dos educandos.

Nessa linha de pensamento, o processo de ensino da disciplina Geografia requer que seus docentes busquem metodologias ativas e estratégias didáticas que reconheçam o aluno como sujeito dotado de historicidade, e que possam conferir maior significação ao processo de ensino-aprendizagem dos conteúdos geográficos atuando, assim, decisivamente para a construção de cidadãos críticos e atuantes. Nessa realidade, é fundamental que o professor torne-se pesquisador da própria prática de ensino e crítico das metodologias desenvolvidas em sala de aula buscando, através da pesquisa, o aperfeiçoamento contínuo da prática docente. 
A Geografia, enquanto disciplina escolar tem o papel de fornecer possibilidades para que o aluno conheça e seja compreender os processos físicos e humanos que tem seus desdobramentos sobre o espaço geográfico. Portanto, trata-se de uma área do saber capaz de atuar decisivamente na formação crítica e cidadã dos educandos, possibilitando-lhes novas formas de entender o espaço vivido e seus processos cotidianos.

O livro didático de Geografia é um recurso de fundamental importância na condução do processo de ensino. No entanto, seu uso demasiado e desvinculado de outros recursos para abordar os conteúdos geográficos acaba por empobrecer a prática docente e prejudicar a aprendizagem dos alunos, pois eles não enxergam motivo algum para estudar aqueles conteúdos que, ao seu ver, não apresentam aplicabilidade real em seu cotidiano. Ressalte-se que, unicamente a presença desse recurso durante as aulas não the confere o status de tradicional, sendo o uso que se faz do livro didático fator determinante que pode vir a reconfigurá-lo no contexto do processo ensino-aprendizagem.

Na concepção de Nunes, Azevedo e Silva (2016, p. 274), o livro didático é um importante instrumento do processo de ensino-aprendizagem tendo em vista que facilita a apropriação de conceitos por meio da linguagem escrita e imagética, e para o ensino de Geografia "sobretudo em escolas públicas, o livro didático torna-se um elemento de grande relevância por permitir o trabalho com diversas informações, como mapas, imagens, gráficos, tabelas, textos e exercícios." Diante disso, depreende-se o papel fundamental desempenhado por este recurso no ensino de Geografia, entretanto, mesmo reconhecendo a funcionalidade deste recurso, os autores ressaltam que "o livro não deve ser considerado o único recurso didático a ser utilizado, tendo em vista a necessidade de diversificar as práticas pedagógicas para dinamizar as aulas e favorecer a construção de conhecimentos pelos alunos".

Diante dessa realidade, e em busca de promover aulas dinâmicas e atrativas no ensino de Geografia, torna-se necessário a exploração de novos recursos didáticos para inserção nas práticas de ensino da disciplina. Os recursos didáticos se constituem enquanto mecanismos facilitadores da aprendizagem e atuam promovendo a interação, mediando o diálogo professor-aluno, a apropriação de conceitos e dinamização das aulas. Assim, seu uso e contribuição mostram-se indispensáveis ao processo de construção do conhecimento geográfico, pois fornecem novos caminhos para a aprendizagem significativa.

Perpassando o viés das discussões relacionadas às práticas pedagógicas, as reflexões acerca da formação docente são de fundamental importância para o desenvolvimento e aperfeiçoamento das metodologias de ensino. Deve-se atentar para o fato de que, cabe ao 
professor a busca pelo aprimoramento de suas práxis em sala de aula, a procura por novos caminhos para a abordagem dos conteúdos de sua disciplina. Dessa maneira, podemos entender que a formação inicial representa o primeiro passo na atuação docente, mas que a formação continuada deve ser incorporada ao cotidiano de cada profissional. Saliente-se que, o aumento das pesquisas sobre temáticas relevantes tais como formação de professores, práticas educativas e recursos didáticos, reforçam as novas demandas do ensino na atualidade.

No contexto da formação inicial para o magistério os Estágios Supervisionados devem ser observados como um leque de possibilidades, pois representam o momento no qual os futuros docentes vivenciam o espaço escolar com todas as suas peculiaridades, tendo a possibilidade de analisar e refletir sobre as práticas de ensino, atentando para as relações teórico-metodológicas que são verificadas nestes espaços de formação.

A realização do estágio nos cursos de licenciatura é umas das exigências da Lei de Diretrizes e Bases da Educação Nacional (n 9394/96) e o cumprimento da carga horária de atividades é requisito básico para a conclusão dos cursos. Segundo Martins e Tonini (2016), a importância do estágio deve-se ao seu objetivo de introduzir o aluno nos espaços escolares e aproximá-lo do dia a dia da escola e das salas de aula da educação básica. Dessa forma, o estágio se apresenta como ferramenta indispensável na formação docente, e também como área de conhecimento que busca aprimorar as relações do licenciando com o ambiente escolar (PIMENTA; LIMA, 2012).

Diante do exposto, este trabalho tem o objetivo de apresentar a experiência vivenciada durante a realização do Estágio Supervisionado II do curso de Licenciatura em Geografia da Universidade Estadual da Paraíba, campus I, Campina Grande. A partir da realidade observada em uma turma de $7^{\circ}$ ano de uma escola pública de Ensino Fundamental II, município de Esperança-PB, foi possível identificar o desânimo e a falta de interesse dos alunos pelas aulas de Geografia.

Considerando o cenário encontrado, e identificado a partir da aplicação de questionários, foi elaborado um projeto de intervenção que consistiu na utilização de imagens como recurso didático para abordar os conteúdos da disciplina, tendo como objetivo tornar as aulas mais dinâmicas e atrativas, dessa forma, permitindo explorar novas possibilidades no processo de ensino-aprendizagem em Geografia, e conferir maior significação à construção do conhecimento geográfico. A escolha deste recurso deveu-se ao fato de observar sua pouca utilização na realidade analisada e por acreditar, assim como Pontuschka, Paganelli e Cacete 
(2007), que a partir das imagens é possível construir um conhecimento geográfico repleto de significado para os alunos.

Diante dessa realidade, explorar as diversas possibilidades práticas apresentadas pelas imagens enquanto recurso didático é imprescindível para o aprimoramento das metodologias que têm base na utilização de imagens, contribuindo também para criar uma nova concepção do uso da imagem como artificio positivo no ensino de Geografia, não mais como mera ilustração, mas como ferramenta auxiliar do processo de aprendizagem. Tal realidade, também permite a disseminação de formas mais promissoras e prazerosas de utilizar a imagem em sala de aula, o que resultará em novas formas de ver e reproduzir a imagem no contexto escolar.

Logo, associando aporte teórico e prática desenvolvida podemos afirmar que, o uso do recurso imagem para as aulas de Geografia se mostrou bastante positivo na turma tendo em vista ter despertado maior interesse nos alunos, que passaram a observar esta disciplina como um conhecimento útil e concreto para seu cotidiano.

\section{A IMPORTÂNCIA DO ESTÁGIO PARA A FORMAÇÃO DOCENTE}

A prática do estágio supervisionado caracteriza-se como momento de estabelecer relações entre teoria e prática frente ao espaço escolar, contexto que possibilita ao aluno conhecer os desafios que se fazem presentes na prática pedagógica e posicionar-se diante dessa realidade. Além disso, constitui-se como uma conjuntura que permite ao futuro professor refletir sobre o suporte dado pela teoria à realização da prática em sala de aula, evidenciando os momentos em que se distanciam e/ou se aproximam, Martins e Tonini (2016) afirmam que:

\footnotetext{
O estágio curricular supervisionado em seu movimento é campo de conhecimentos pedagógicos, envolvendo a universidade, a escola, os estagiários, tendo os professores da educação básica uma preocupação central com os fenômenos do ensinar e do aprender. Representa a inserção do professor em formação no campo da prática profissional para ter a experiência da docência, vivenciando a regência de classe e a realidade da sala de aula, que são saberes fundamentais na construção da identidade docente (p. 99).
}

Nessa perspectiva, o estágio supervisionado nos cursos de licenciatura se configura como uma prática de fundamental importância para a formação docente, não apenas por sua obrigatoriedade à formação dos futuros profissionais, mas por ser um espaço amplo e plural onde o aluno tem o primeiro contato com as diversas variáveis que constituem processo de ensino-aprendizagem na Educação Básica. Dessa forma, cumpre a função de apresentar o 
espaço da sala de aula e a dinâmica dos processos que transitam nos espaços da escola aos licenciando despertando e possibilitando reflexões múltiplas acerca das realidades que se fazem presentes no âmbito da escola. Nesse contexto.

O estágio, então, deixa de ser considerado apenas um dos componentes e mesmo um
apêndice do currículo e passa a integrar o corpo de conhecimentos do curso de
formação de professores. Poderá permear todas as suas disciplinas, além de seu
espaço específico de análise e síntese do final do curso. Cabe-lhe desenvolver
atividades que possibilitem o conhecimento, a análise, a reflexão do trabalho
docente, das ações docentes, nas instituições, a fim de compreendê-las em sua
historicidade, identificar seus paralelos, os impasses que apresenta, as dificuldades.
Dessa análise crítica, à luz dos saberes disciplinares, é possível, apontar as
transformações necessárias no trabalho, nas instituições (PIMENTA; LIMA, 2012,
p. 55).

As múltiplas faces que compõem o processo de ensino-aprendizagem na instituição escolar são eminentemente dinâmicas e traduzem descrições provisórias da realidade, tendo em vista tratar-se de um processo imensurável composto por variáveis que assumem valores e significados distintos conforme a realidade dos sujeitos envolvidos em dado espaço e tempo. Nesse sentido, o estágio curricular que possibilita aos seus agentes perceber tais variáveis nas escolas e refletir acerca da forma como escola tem trabalhado com elas.

Segundo Barros, Silva e Vásquez (2011, p. 511), o estágio proporciona a construção de diversos conhecimentos e práticas no âmbito da formação docente, dentre eles "atitudes críticas e reflexivas a respeito do processo de ensino e aprendizagem, proporcionando a construção de atitudes e concepções questionadoras e transformadoras referentes ao ensino." O estágio, nesse sentido, se mostra como espaço de ação e reflexão, imprescindível à formação docente. De acordo com Rodrigues (2015), a formação docente constitui-se em um meio pelo qual o professor aprende e desenvolve habilidades próprias da sua prática de ensino, assim,

[...] a formação do professor deve ser vista não só como uma habilitação para qualificá-lo como um profissional, mas também como o desenvolvimento de ações que assegurem uma constante retomada dos conhecimentos específicos com os quais trabalha, dando a possibilidade de reflexões em torno da sua prática de forma a corrigir os problemas encontrados (p. 3).

A observação e intervenção na realidade verificada nos campos de estágio permite ao aluno analisar metodologias que compõem o processo didático, as perspectivas e desafios apresentados por estas na construção do conhecimento, estimulando a reflexão crítica sobre as possibilidades e novas formas de abordagem dos conteúdos na sala de aula, o implica no aperfeiçoamento das práticas de ensino e evidencia o estágio como espaço de formação 
docente e campo de pesquisa, onde a teoria e a prática devem se apoiar no fornecimento de subsídios teóricos-metodológicos para as práticas desenvolvidas na sala de aula e no espaço escolar como um todo. Nessa perspectiva,

\begin{abstract}
A pesquisa no estágio, como método de formação de futuros professores, se traduz, de um lado, na mobilização de pesquisas que permitam a ampliação e análise dos contextos onde os estágios se realizam; por outro lado, e em especial, se traduz na possibilidade de os estagiários desenvolverem postura e habilidades de pesquisador a partir das situações de estágio, elaborando projetos que lhes permitam ao mesmo tempo compreender e problematizar as situações que observam. Esse estágio pressupõe outra postura diante do conhecimento, que passe a considerá-lo não mais como verdade capaz de explicar toda e qualquer situação observada, o que tem conduzido estagiários a dizerem o que os professores devem fazer. Supõe que se busque novo conhecimento na relação entre as explicações existentes e os dados novos que a realidade impõe e que são percebidos na postura investigativa (PIMENTA; LIMA, 2012, p. 46).
\end{abstract}

As discussões nos cursos de formação de professores por muitas vezes se distanciam das realidades que estão sendo vivenciadas nos espaços escolares, seja pela dificuldade em lidar com as diferentes facetas do processo de aprendizagem, seja pelo caráter provisório das pesquisas que tomam como base os sujeitos escolares e suas trajetórias. Diante dessa realidade, o estágio possibilita a construção de uma “ ponte” entre os saberes acadêmicos e a dinamicidade dos processos que estão ocorrendo nas instituições de ensino, o permite que aos componentes de estágio discutir propostas, pesquisas, metodologias críticas e estratégias didáticas conforme as possibilidades encontradas em cada área do conhecimento que compõem a Educação Básica.

Nesse sentido, a formação docente "deve se pautar na perspectiva investigativa, na qual a pesquisa, assumida como princípio científico e educativo, apresenta-se como uma proposição metodológica fundamental para o rompimento das práticas de reprodução" (BARREIRO; GEBRAN, 2006, p. 118).

Assim, pode entender a construção de projetos e planos de intervenção, como debate e contribuição necessários acerca de alternativas de metodologias de ensino, evidenciando aspectos do processo didático relacionados, por exemplo, às ações docentes e pesquisas no espaço escolar. Nesse sentido, o estágio supervisionado se mostra uma importante prática de formação de professores, pois não só permite o desenvolvimento de novas estratégias didáticas a partir de novos projetos metodológicos, como também permite o aperfeiçoamento das já existentes, seja na escola básica, ou nos espaços acadêmicos. 


\section{A IMAGEM COMO RECURSO DIDÁTICO PARA OS CONTEÚdOS DE GEOGRAFIA}

A Geografia pode ser entendida como a ciência que estuda o homem e sua relação com a natureza, investigando os elementos naturais e antrópicos, procurando explicar os fenômenos e os processos que se apresentam diante dessa realidade (VITTE; SILVEIRA, 2010).

Para tanto, a Geografia perpassa por diversas áreas do conhecimento para explicar os fatos e os processos que ocorrem no espaço geográfico. Nesse contexto, a Geografia induz a um debate crítico da realidade, buscando apresentar os pros e os contras dos fenômenos espaciais, em ordem social, econômica e ambiental alertando a sociedade sobre as permanências e transformações provocadas pelo homem. No âmbito escolar, a importância do ensino de Geografia está em fornecer ao educando subsídios teóricos e práticos que o permitam entender de forma crítica a realidade onde vive, compreendendo seu papel como cidadão e como agente modificador do espaço, atentando para sua responsabilidade social e humana, no tempo e no espaço (BRITO, 2012).

Todavia, em decorrência de práticas mnemônicas e distanciadas do cotidiano dos alunos a Geografia é frequentemente lembrada como uma disciplina chata e enfadonha relacionada apenas a nomenclaturas difíceis e desnecessárias para a vida real (MORAIS; MELO, 2015). Essa maneira de tratar os conhecimentos geográficos gera entraves no aprendizado e termina por cristalizar ainda mais o estereótipo negativo atribuído à disciplina, o que compromete a construção concreta e significativa dos conhecimentos geográficos.

O movimento de renovação da prática de ensino em Geografia busca a aplicação de novas propostas metodológicas e estratégias didáticas visando tornar as aulas atrativas e conferir maior significação ao processo de construção do conhecimento geográfico (SILVA; BRAGA; SOARES, 2017).

Nessa perspectiva, o ensino de Geografia deve se apresentar com dinamicidade nos espaços de sala de aula, com práticas que se renovem conforme as necessidades de ensino e as realidades da atualidade, buscando fornecer ao estudante conhecimentos e aptidões que lhe permitam entender a realidade do seu espaço vivido, e o mundo global, em seus processos naturais e humanos (BRITO, 2012). Para tanto, o professor deve se utilizar de metodologias diferenciadas como aulas de campo, experimentos práticos, construção de mapas e maquetes, documentários, utilizando sempre de forma ativa, coletiva e participativa, permitindo assim 
maior efetividade no processo de aprendizagem evitando, dessa forma, basear sua prática apenas no livro didático.

Nesse sentido, os recursos didáticos se mostram como ferramentas indispensáveis ao ensino, configurando-se como auxiliadores no trabalho com os conteúdos da disciplina, promovendo maior interação entre os alunos e os demais agentes envolvidos com seus usos, além disso, facilitam a percepção e a construção do conhecimento em Geografia (ARRUDA, 2018). Corroborando com esta ideia, Tulio (2013) afirma que a utilização de recursos como imagens, filmes, documentários e saídas de campo, visam tornar as aulas da disciplina mais atrativas, permitindo uma aprendizagem mais efetiva. Dessa forma, o uso de recursos didáticos aulas de Geografia permite a articulação entre o conteúdo e a realidade, promovendo a assimilação dos conceitos trabalhos na disciplina escolar.

Dentre os recursos, os mais facilmente encontrados estão as imagens, sendo os mais comuns nas salas de aula: fotografias, filmes, charges, mapas e vídeos. A imagem tem no ambiente escolar importante função, visto a facilidade em ser memorizada e remeter à realidade e ao espaço vivido dos educandos (SILVA; BRAGA; SOARES, 2017). A importância das imagens no processo de comunicação data do início da formação de algumas sociedades onde as pinturas rupestres, antes mesmo da presença de um sistema de escrita, foram a forma de registar informações, coletivizar pensamentos e sentimentos naquele momento histórico (RIBEIRO; LIMA, 2009).

Nessa perspectiva, para Silva, Braga e Soares (2017), a imagem teve importante papel na história da humanidade mostrando grande influência na comunicação durante períodos nos quais não havia sistemas de escritas e quando a maior parte da população era predominantemente analfabeta, tendo como principais suportes madeiras, pedras, argilas, ossos, couros, metais e papéis. Nessa linha de pensamento, a imagem é de fundamental importância para a formação de ideias, facilitando a comunicação e permitindo a melhor percepção dos processos visíveis do espaço que, no entanto, podem estar distantes da realidade do aluno.

Ainda para Silva, Braga e Soares (2017) a importância da imagem está ligada ao seu papel facilitador no processo de ensino-aprendizagem, servindo tanto de acompanhamento para determinados textos ou fala, ou apresentando informações sobre si própria. No entanto, os autores ressaltam que quando não acompanhada por textos, as imagens podem levar a interpretações distintas e até mesmo para a fuga do contexto em que se apresenta. A inserção das imagens como estratégia didática nas aulas de Geografia traz grande contribuição para o 
estudo na disciplina, pois permite o contato visual com as dinâmicas ocorridas no espaço, tendo em vista que a maior parte dos processos presentes na dinâmica espacial não se fazem presentes nos livros didáticos ou são vistas nas aulas de campo da disciplina. Nesse sentido, as potencialidades das imagens devem ser exploradas e valorizadas nas aulas do componente curricular de Geografia.

Nessa conjuntura, a utilização de imagens como recurso didático, vinculados a um planejamento prévio e objetivos claros, torna a aula mais dinâmica e atrativa aos educandos, em relação à aula sem o uso de imagens. E por ter um porte observador analítico, de vertente crítica e atuante nas dinâmicas da sociedade, a Geografia pode utilizar as imagens como ferramenta aliada na análise do espaço, conferindo maior significação na construção do conhecimento na disciplina (ZATTA; AGUIAR, 2009).

\section{METODOLOGIA}

\section{Caracterização do espaço escolar}

A Escola Municipal de Ensino Fundamental Joventino Batista Monteiro é uma instituição pública destinada a acolher alunos do município de Esperança, PB, a unidade escolar está localizada a $12 \mathrm{~km}$ da sede do município no Distrito de Massabielle (Figura 1).

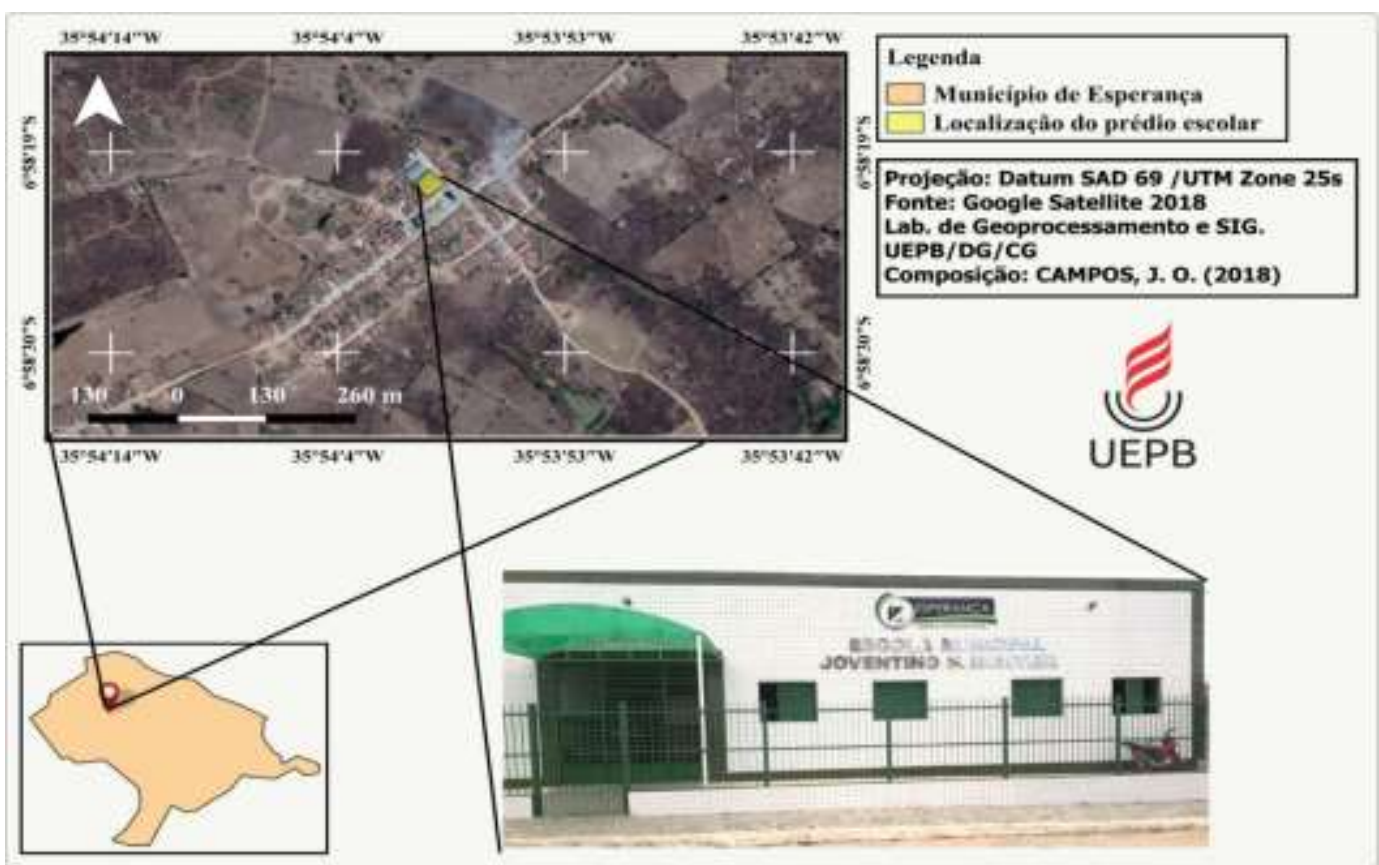

Figura 1- Localização da unidade escolar no Distrito de Massabielle/ Esperança - PB.

Fonte: Os autores (2018).

A escola oferta educação básica nas etapas de Educação Infantil, Ensino Fundamental I e II, disponibilizando também a Educação para Jovens e Adultos (EJA). Quanto à estrutura 
física a escola dispõe de 08 salas de aula (Figura 2), sala dos professores, refeitório, pátio, biblioteca, 02 banheiros e ginásio poliesportivo.

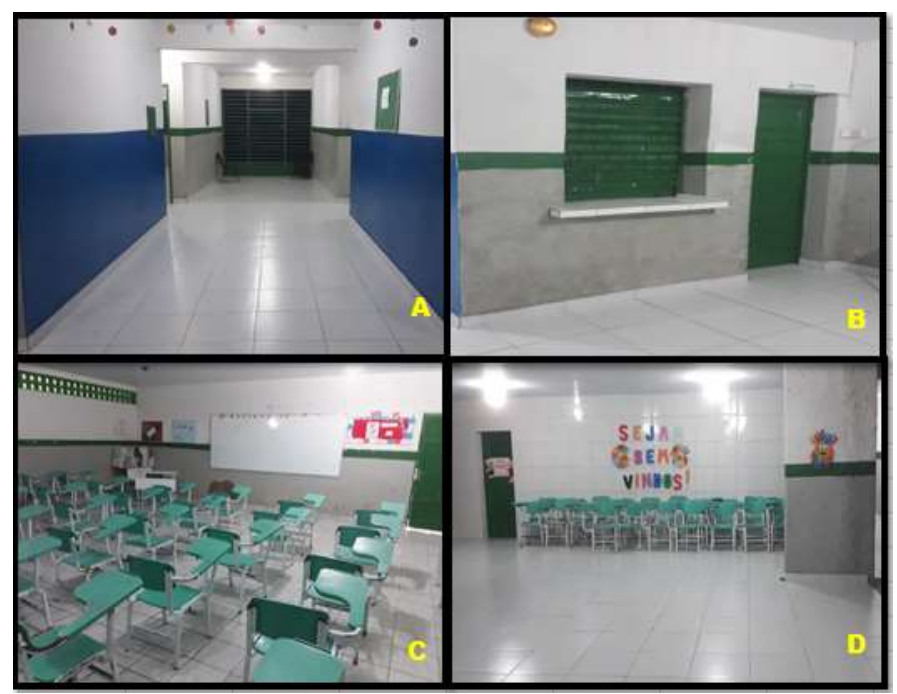

Figura 2 - A - Entrada da escola. B - Refeitório da instituição. C - Organização das salas de aula. D Pátio da escola. Fonte: Os autores (2018)

Os 268 alunos que frequentam esse espaço escolar nos turnos da manhã, tarde e noite são, em maioria, de baixa renda e residem na zona rural, próximo a localidade da escola. Conforme exposto abaixo:

\begin{tabular}{|l|c|c|c|c|}
\hline \multirow{2}{*}{ Etapa } & \multicolumn{2}{c|}{ Turno } & Noite & $\begin{array}{c}\text { Total de alunos } \\
\text { por turno }\end{array}$ \\
\cline { 2 - 5 } & Manhã & Tarde & - & 48 \\
\hline Ensino Infantil & - & 48 & - & 72 \\
\hline $\begin{array}{l}\text { Ensino Fundamental I } \\
\text { (séries iniciais) }\end{array}$ & - & 72 & - & 125 \\
\hline $\begin{array}{l}\text { Ensino Fundamental II } \\
\text { (séries iniciais) }\end{array}$ & 125 & - & 23 & 23 \\
\hline $\begin{array}{l}\text { Educação de Jovens e } \\
\text { Adultos (EJA) }\end{array}$ & - & - & 268 \\
\hline
\end{tabular}

Quadro 1- Distribuição dos alunos matriculados por turno e etapa da Educação Básica. Fonte: Os autores (2018)

A turma envolvida nesta proposta didático pedagógica foi de $7^{\circ}$ ano do Ensino Fundamental. De perfil diversificado a turma era composta por 27 alunos, sendo16 meninas e 11 meninos, com faixa etária entre 12 e 14 anos.

Ademais, o público atendido e que reside em localidades mais distantes da unidade escolar é transportado por ônibus escolares oferecidos pelo município em todos os turnos de funcionamento da escola. 


\section{Procedimentos Metodológicos}

Tendo em vista tratar-se um dos momentos mais importantes da formação para o magistério, o Estágio Supervisionado tem como objetivo oportunizar a regência dos futuros professores em turmas de Ensino Fundamental e Médio. Nesse sentido, se faz necessário que o estagiário faça um planejamento prévio das atividades que pretende desenvolver durante seu período de regência na escola na qual desenvolverá seu estágio.

Diante do mencionado, buscou-se conhecer os alunos da turma de $7^{\circ}$ ano, turno manhã. Inicialmente foi aplicado um questionário semiestruturado junto aos alunos, o objetivo foi identificar suas potencialidades e dificuldades relacionadas ao aprendizado dos conteúdos geográficos, bem como suas perspectivas e anseios com relação à disciplina. Ressalte-se que, as sugestões vindas dos alunos para a realização das aulas foram levadas em consideração para a organização e implementação do plano de ação elaborado.

Observando a pouca interação da turma no desenvolvimento dos conteúdos foi possível verificar o desânimo e desinteresse no que concerne à realização das atividades contidas no livro de didático de Geografia, entre as reclamações mais frequentes podem ser citadas as leituras longas, cansativas e de difícil compreensão. Nesse contexto, o projeto de intervenção consistiu na utilização de imagens como recurso didático para trabalhar os conteúdos da grade curricular do componente.

Os recursos utilizados foram: fotografias, mapas, vídeos, slides e desenhos. Os conteúdos trabalhos seguiram a ordem didática apresentada pelo livro didático, seguida pelo professor turma.

Os conteúdos foram discutidos mediante objetivos determinados de aprendizagem para cada assunto, conforme sintetizado no Quadro 2:

\begin{tabular}{|c|c|}
\hline Conteúdos & Objetivos \\
\hline $\begin{array}{l}\text { Concentração industrial e expansão da } \\
\text { indústria }\end{array}$ & $\begin{array}{l}\text { Identificar as características do processo de } \\
\text { concentração e expansão da indústria }\end{array}$ \\
\hline Urbanização e migração & $\begin{array}{l}\text { Discutir a relação da migração com } 0 \\
\text { crescimento acelerado das cidades }\end{array}$ \\
\hline Meios de transporte & $\begin{array}{l}\text { Identificar os principais meios de transporte } \\
\text { no Brasil, características, históricos e usos }\end{array}$ \\
\hline Comunicação no Brasil & $\begin{array}{l}\text { Discutir características, aplicações } \\
\text { funcionamento de diferentes meios de } \\
\text { comunicação no Brasil }\end{array}$ \\
\hline Região Nordeste & $\begin{array}{l}\text { Identificar os aspectos socioeconômicos e } \\
\text { ambientais da Região Nordeste }\end{array}$ \\
\hline
\end{tabular}

Quadro 2- Síntese de conteúdos discutidos durante o período de regência no estágio, com objetivos determinados. Fonte: Os autores (2018). 
Cabe destacar que as aulas foram ministradas tomando como norte o conhecimento prévio dos alunos acerca dos conteúdos trabalhados. Dessa forma, foram desenvolvidas as seguintes atividades: discussões em grupo acerca dos conteúdos, possibilitando troca e construção de conhecimento; exibição e leitura de imagens como recurso didático, exercícios escritos e orais. A partir de orientações do professor regente sobre a dinâmica da turma, foi feita a seleção dos conteúdos e as atividades a serem desenvolvidas durante as aulas. $\mathrm{O}$ professor regente participou ativamente do desenvolvimento das atividades e da análise dos resultados durante a execução do projeto de intervenção.

Diante disso, os resultados deste trabalho são compostos pela análise dos questionários, apresentação e discussão das experiências desenvolvidas em sala aula a partir do desenvolvimento do projeto implementado pelo estagiário em consonância e com a colaboração do professor regente da turma.

\title{
RESULTADOS E DISCUSSÕES
}

A partir da aplicação dos questionários foi possível observar que vários alunos afirmaram gostar da disciplina, no entanto não justificaram sua opinião. Esse fato mostra que a Geografia é percebida por muitos alunos como apenas “mais uma disciplina”, e que apesar de afirmarem gostar desse conhecimento eles não tem argumentos concretos para justificar sua resposta.

Dentre as respostas de alguns alunos temos:

\author{
Aluno 1: "Geografia é importante porque estuda de tudo" \\ Aluno 2: "a Geografia está no clima" \\ Aluno 3: " a Geografia está nas matas" \\ Aluno 4: " a Geografia estuda o espaço geográfico" \\ Aluno 5:" a Geografia estudas as montanhas"
}

Percebe-se então que alguns alunos possuem dificuldades em apontar o objeto de estudo da Geografia, de modo que associam sua abordagem a elementos isolados do espaço.

Uma quantidade menor de alunos disse não gostar da disciplina e justificaram como sendo chata, difícil de entender, e sem importância, outra parte da turma se manteve indiferente na opinião, e também não justificou. Dentre as justificativas apontas no questionário pelos alunos que não gostam da disciplina, têm-se: 
Aluno 1: "A Geografia não faz parte do cotidiano e é muito chata as atividades de geografia não é interessantes para mim."

Aluno 2: "Eu não gosto porque é difícil."

Aluno 3: "Não gosto de Geografia porque sinto dificuldade"

Realidade semelhante foi verificada por Oliveira et.al. (2013) ao realizar sua pesquisa com alunos do Ensino Básico em uma escola de Campina Grande-PB. Os resultados do estudo mostraram grande semelhança com a realidade da turma em discussão, uma vez que vários educandos afirmaram não gostar de Geografia atestando sua pouca utilidade no cotidiano.

Muitos são os casos em que a falta de entusiasmo do professor na sala de aula e a dificuldade de trabalhar os conteúdos de forma dinâmica contribuem para tornar a aula enfadonha. De acordo com Libâneo (1994), inúmeras são as aulas e tarefas não atrativas que levam o aluno a perder o interesse e o gosto pela disciplina, e em parte dos casos não há relação entre os conhecimentos abordados e as experiências prévias que os alunos já carregam. Dessa forma, os alunos não se sentem motivados para estudar determinado conteúdo, como resultado procuram apenas decorar os temas abordados.

Sobre a percepção acerca de qual o objeto de estudo da Geografia, a maioria respondeu como sendo "o espaço geográfico", um número intermediário respondeu que estudava “ chuvas, relevo, tecnologias e as matas", a menor parte disse não lembrar dos elementos estudados pela Geografia.

Em resposta para outra questão, a maioria dos alunos diz considerar que a Geografia não faz parte do cotidiano, a menor parte respondeu que sim, afirmando que a mesma estava presente na própria escola, nas montanhas, no clima e nas matas, outros responderam que a Geografia só está presente em alguns momentos de suas vidas. Silva e Melo (2016) apontam que a Geografia, antes de tudo, deve levar o aluno a se reconhecer como cidadão na sociedade e como integrante dela, além disso, é necessário que o educando conheça o campo de estudo da Geografia e perceba sua presença em seu cotidiano. Dessa forma, percebe-se aqui um distanciamento entre teoria e prática, observado na resposta dos alunos, que não reconhecem a Geografia como parte do seu dia a dia.

Diante desse cenário, é inevitável a reflexão acerca do trabalho desenvolvido pelo professor na sala de aula e sua didática de ensino. É necessário compreender que muitas vezes as metodologias aplicadas pelo professor não permitem a construção do conhecimento, 
mesmo por meio de aulas dinâmicas e planejadas, sendo necessário a renovação das práticas desenvolvidas com os alunos (SILVA; MELO, 2016).

No que concerne às dificuldades em estudar os conteúdos geográficos, todos os alunos afirmaram sentir dificuldade, justificando ter que escrever muito e fazer leituras longas fato que evidencia a deficiência em outras disciplinas fundamentais para a formação dos educandos, a exemplo do Português. Nesse contexto, alguns alunos apresentaram sugestões para as aulas de Geografia: utilizar mapas, globos, filmes, brincadeiras, dinâmicas, e escrever menos textos e fazer mais exercícios. Esse cenário de respostas fundamentou a proposta de intervenção, tendo por base o uso de imagens como recurso didático. A partir desse diagnóstico, as aulas foram planejadas considerando o uso do recurso didático imagem e as necessidades dos alunos da turma.

Iniciando as intervenções, o conteúdo abordado foi " Concentração industrial $e$ expansão da indústria no Brasil". O primeiro passo para o desenvolvimento da aula foi a sintetização do assunto em uma apresentação de slides, o material contemplou os principais pontos a serem discutidos em sala de aula. Em seguida, foram selecionadas imagens que retratavam o percurso histórico da indústria no país e sua expansão, apresentando suas vantagens e desvantagens para o período. Salienta-se que, as imagens não foram escolhidas de forma aleatória e desconectada do contexto da discussão, mas sempre contemplando a sintetização organizada em slides, buscando o encadeamento lógico e coerente para a aula bem como para a exposição do tema visando o alcance dos objetivos de cada encontro. Segue uma das imagens utilizadas como recurso didático junto aos alunos do $7^{\circ}$ ano:

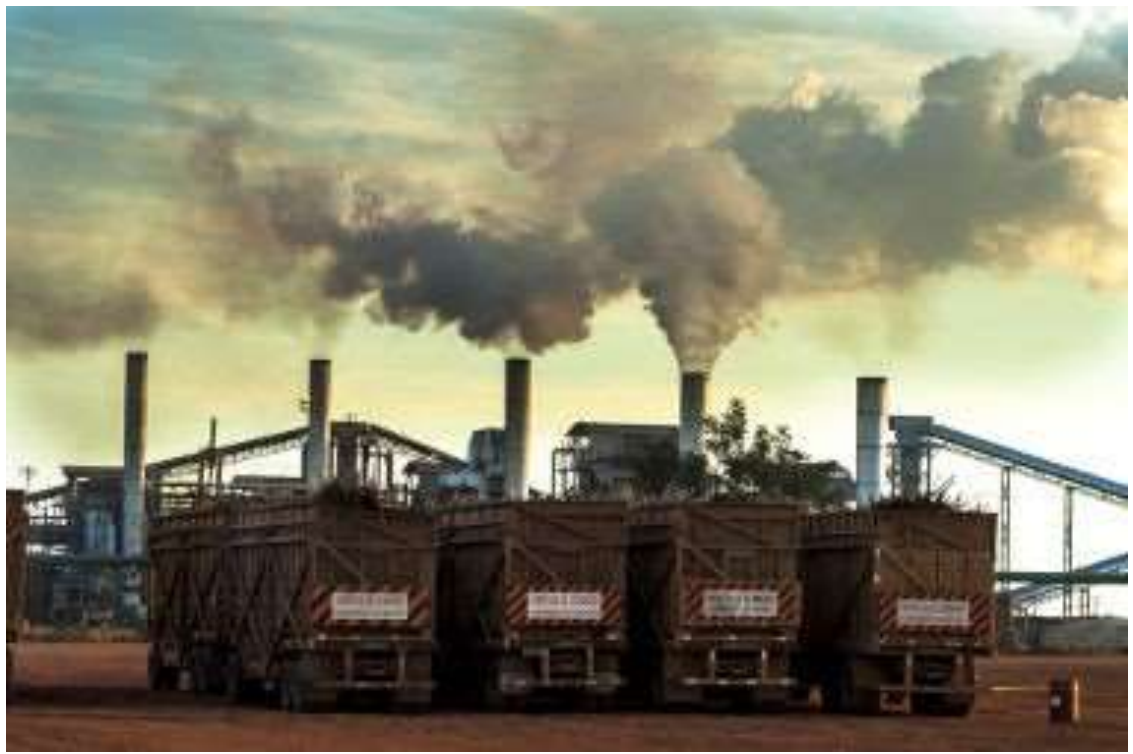

Figura 3 - Usina de etanol no Mato Grosso característica da desconcentração da indústria. Fonte: PENA (2019). 
Os conhecimentos prévios que os alunos trouxeram para nossa discussão foram de extrema relevância para a abordagem do conteúdo, já que a partir dessa prática a tendência é que os educandos relacionem a discussão com a sua própria realidade facilitando o entendimento da temática.

No decorrer do trabalho com o conteúdo, foi possível verificar o aumento gradativo da participação dos alunos nas discussões. As falas estavam relacionadas de forma direta à leitura das imagens apresentadas, os questionamentos emergiam de forma natural possibilitando uma análise mais cuidadosa do conteúdo oportunizando, assim, um aprendizado mais significativo e a construção de conceitos importantes para a compreensão dos conteúdos geográficos. Resultados semelhantes foram verificados por Farinha e Vieira (2015) no estado do Mato Grosso do Sul, e Silva, Braga e Soares (2017) em Pernambuco, no trabalho com imagens nas aulas de Geografia no Ensino Fundamental.

Dando seguimento às aulas, o segundo conteúdo abordado foi "Urbanização $e$ migração". Neste conteúdo foram utilizadas imagens que retrataram o processo de urbanização no Brasil, dando destaque para suas características, pontos positivos e negativos. As primeiras imagens foram constituídas de charges e fotografias, apresentando aspectos da migração, crescimento das cidades do país, o fenômeno do êxodo rural e suas consequências. A Figura 4 é uma das imagens utilizadas.

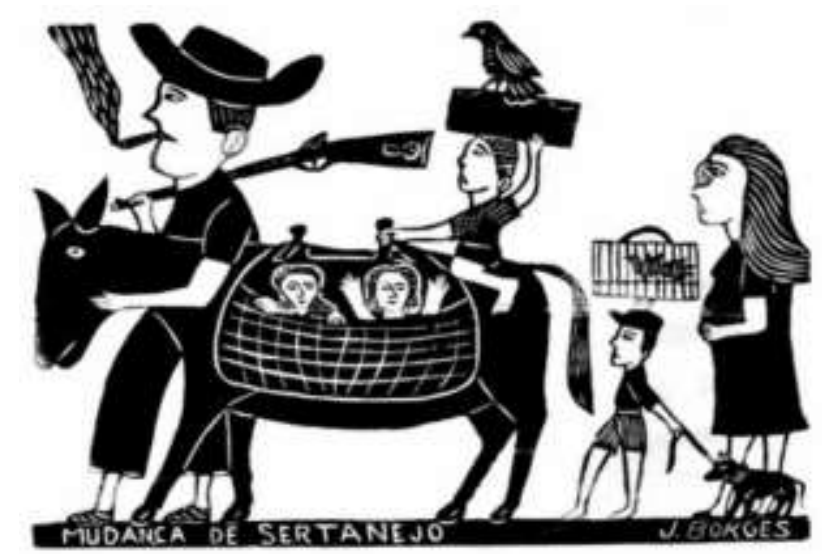

Figura 3 - Ilustração representativa do fenômeno êxodo rural. Fonte: TV Escola (2015).

Em algumas imagens os alunos se mostraram surpresos com as cenas retratadas, a exemplo das cenas de pobreza e miséria verificadas em algumas favelas e espaços rurais do país. Segundo os alunos, aquelas imagens eram diferentes das imagens do livro, pois apresentam outra realidade, o que nos leva a questionar se o livro didático de Geografia está preocupado em retratar as realidades ou apresentar contextos específicos e convenientes ao 
Estado. A esse respeito um aluno relata que: "Eu pensei que ninguém passava fome, nunca tinha visto pessoas assim, eu vi no jornal uma vez, mas pensei que era longe”. A fala do aluno demonstra que o mesmo desconhecia os quadros de pobreza e miséria ainda existentes no Brasil.

A resposta ao uso desse recurso didático foi positiva, os alunos demonstraram interesse em interagir e discutir as imagens. Vários foram os questionamentos estabelecendo ligações entre as imagens e cenas cotidianas, fato que ampliou de forma significativa os horizontes de abordagem do conteúdo em discussão.

Finalizando a abordagem acerca do conteúdo "Urbanização e migração" foi realizada uma atividade escrita sobre o conteúdo trabalhado.

Seguindo a escolha pelo uso das imagens enquanto recurso didático, a atividade proposta foi elaborada mediante a utilização de imagens diversas e valorizando a perspectiva de interpretação dos alunos sobre cada uma delas, os resultados foram satisfatórios e o modo de apresentação das questões agradou bastante os estudantes.

Nesse mesmo sentido, Farinha e Vieira (2015) observaram resultados semelhantes no trabalho com imagens e a categoria geográfica de lugar, no decorrer da aula e na realização das atividades propostas, em Dourados - MS, contexto em que os autores tomaram as imagens como recurso para abordar o espaço vivido dos alunos.

A imagem mostra o momento da realização da proposta, a aula é ministrada pelo professor em formação, estagiário na turma e idealizador deste plano de intervenção pedagógica:

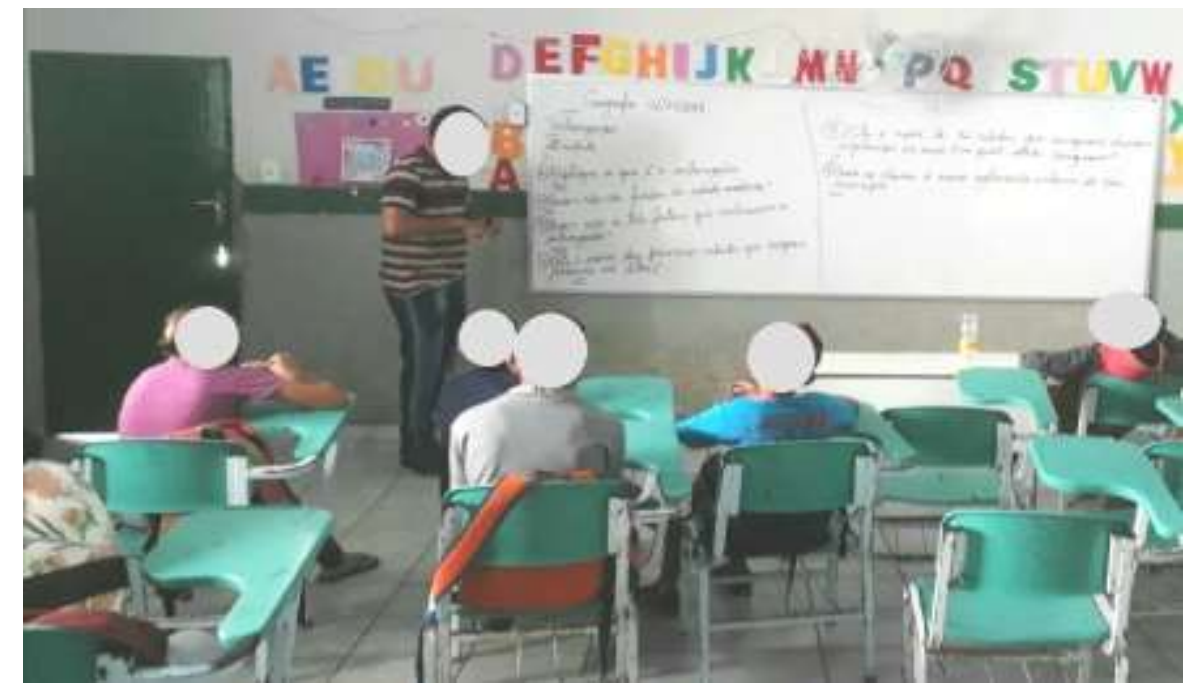

Figura 5- Atividade escrita sobre o conteúdo. Fonte: Os autores (2018) 
No terceiro conteúdo abordado, "Meios de transporte", foram utilizadas imagens retratando os principais meio de transporte no Brasil e no mundo, e ilustrações para discussão de conceitos presentes no livro didático. Por meio das imagens foram apresentados os modelos de transportes dos mais antigos aos mais recentes, proposta também verificada no livro didático, no entanto, sem o uso de ilustrações diversificadas para apresentar a linha do tempo.

A aula foi iniciada com a discussão dos conhecimentos prévios dos alunos a respeito do tema, seguindo com a apresentação das imagens e discussão do conteúdo, para encerrar foi realizada uma atividade escrita com uso de imagens e proposta de análise dos meios de transporte no Brasil. Ao longo da aula os alunos apresentaram interação, diálogo com o professor na discussão dos pontos apresentados nas imagens, mostrando interesse e envolvimento nas atividades, a correção das atividades evidenciou a apropriação dos conceitos trabalhados na aula pela maior parte dos alunos, conforme também foi analisado por Silva, Braga e Soares (2017) no trabalho com imagens, na cidade de Limoeiro - PE, onde foram ministras aulas com e sem utilização de imagens, para fins de comparação.

O conteúdo "Comunicação no Brasil", foi abordado a partir do percurso evolutivo dos meios de comunicação e da importância do setor para o país. O uso de imagens impressas chamou bastante a atenção dos alunos, que puderam observar características e particularidades dos meios de comunicação, muitos dos quais nunca tiveram acesso em seu cotidiano, nem mesmo através de imagens. Durante a aula, os alunos se mantiveram atentos para a discussão do conteúdo e assimilação com uso das imagens, no entanto, percebeu-se maior interesse pelas imagens impressas, as quais puderam manusear e observar de diferentes formas.

Neste conteúdo para além das imagens impressas foi utilizado o recurso didático vídeo, que desponta como um recurso metodológico bastante eficaz. Para esta abordagem o filme apresentado para os alunos foi "A evolução da comunicação" (Disponível em: https://www.youtube.com/watch?v=3otNmqvX0jk). Todavia, de acordo com Fantin, Tauscheck e Neves (2010), cabe salientar que tal ferramenta em si não traz grandes mudanças, pois é o professor que tem o papel de mobilizar o aluno até o conhecimento e orientá-lo para a construção do mesmo. Isto demonstra que o vídeo não surge para a resolução dos problemas do aprendizado ou como um "produtor de conhecimento", sua função é de conduzir a aula para um caminho mais proveitoso e participativo. 
Por fim, foi solicitada uma atividade escrita a respeito do conteúdo trabalhado, onde foi possível constatar a compreensão da importância dos meios de comunicação por parte dos alunos. Durante a aula os alunos se mantiveram atentos à exibição das imagens, discussão do conteúdo e aos elementos presentes no vídeo, mostrando interação e interesse em desenvolver as atividades propostas.

Nesse mesmo sentido, as pesquisas realizadas por Ferreiro e Pátaro (2010) em Campo Mourão - PR, assim como os estudos de Morais e Melo (2015) em Campina Grande - PB, evidenciam resultados semelhantes obtidos pela utilização de imagens e vídeos como fortes aliados do processo de ensino-aprendizagem em Geografia.

Finalizando o período de regência na turma a abordagem do conteúdo "Região Nordeste" foi realizada com o uso de mapas, vídeos e fotografias, que buscaram retratar as paisagens das sub-regiões do Nordeste: zona da mata, agreste, sertão e meio-norte, onde foi dado ênfase aos aspectos físicos e humanos do espaço nordestino.

Após a sondagem dos alunos e apresentação dos objetivos prévios, foram discutidos os mapas e fotografias de espaços do Nordeste. Posteriormente, foram exibidos dois vídeos de curta duração:

a) "O coronel $\quad$ e $o$ lobisomem" (Disponível em: https://www.youtube.com/watch?v=qLTzbfopMmE), trazendo para a sala de aula uma animação em forma de versos de cordel, possibilitando que as discussões gravitassem sobre questões referentes às desigualdades sociais e a figura do coronel no Nordeste.

b) "Vida Maria" (Disponível em: https://www.youtube.com/watch?v=yFpoG_htum4), é um curta metragem em forma de animação que aborda a vida no sertão. O objetivo da exibição desse filme foi discutir sobre a problemática da educação no Nordeste, as desigualdades sociais e a convivência com o Semiárido.

Os alunos se mantiveram atentos às cenas, e a todo momento foi possível observar a relação que estabeleciam com paisagens do cotidiano. Demonstraram atenção nas discussões, com interações múltiplas discutindo as cenas que foram retratadas nas animações, o que facilitou a apropriação dos conceitos trabalhados e maior compreensão da linguagem portada no livro didático. Os resultados aqui observados se aproximam dos resultados verificados por Ferreira e Pátaro (2010), se diferenciando da experiência desses pesquisadores apenas por se tratar de vídeos de curta duração com, no máximo, 10 minutos de duração. 


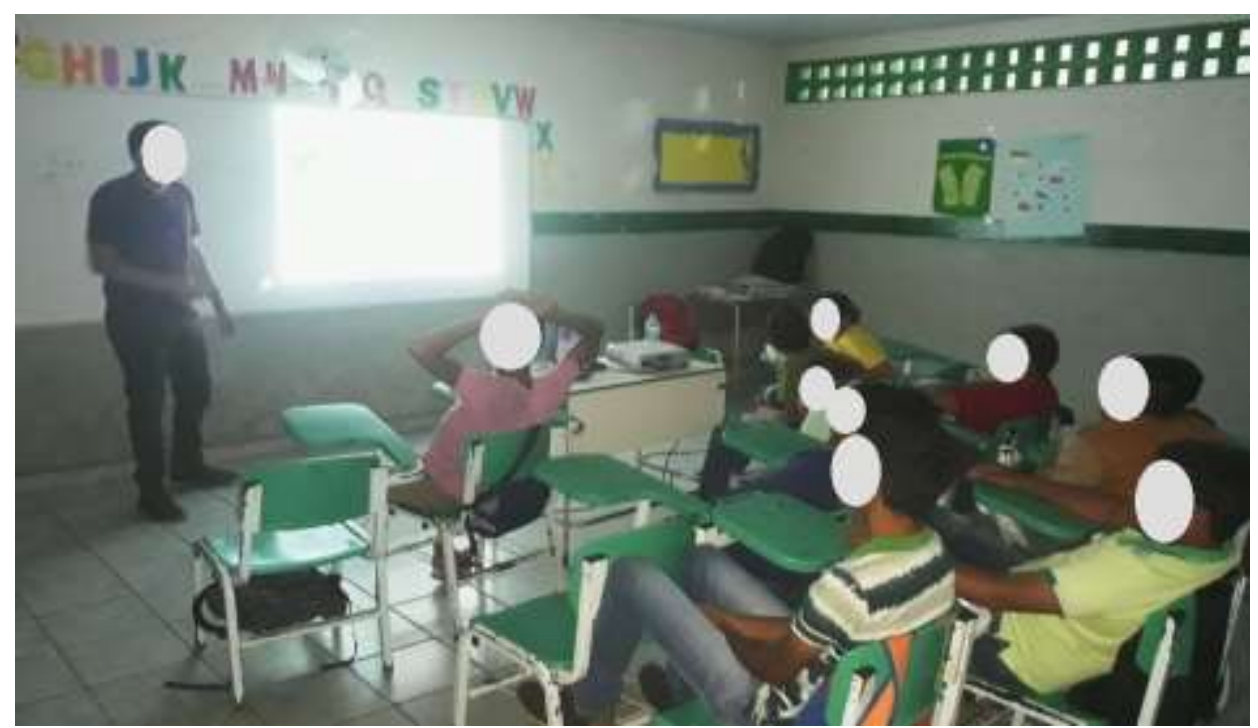

Figura 6- Exibição do curta-metragem "Vida Maria”. Fonte: Os autores (2018).

Assim, a implementação desse plano de intervenção pedagógica nas aulas de Geografia, além de possibilitar uma formação mais sólida para o estagiário, contribuiu positivamente para o aprendizado da turma. De forma geral, os resultados obtidos com este trabalho estão de acordo com as pontuações de Ribeiro e Lima (2009) e Zatta e Aguiar (2009), que evidenciam o uso de imagens como ferramenta didática para as aulas de Geografia, possibilitando uma maior compreensão dos temas e conceitos abordados, o que pôde ser verificado ao longo da experiência do estágio. Os resultados obtidos na experiência de intervenção com o uso de imagens nas discussões dos conteúdos se assemelham aos dados obtidos nas pesquisas de desenvolvidas por Ferreira e Pátaro (2010), Farinha e Vieira (2015), Morais e Melo (2015) e Silva, Braga e Soares (2017), corroborando a efetividade e os resultados nas experiências com o uso de imagens nas aulas, conduzindo à novas perspectivas no processo de ensinoaprendizagem em Geografia.

\section{CONSIDERAÇÕES FINAIS}

Tendo em vista os desdobramentos do plano de trabalho proposto, podemos afirmar que os objetivos almejados para o uso das imagens como recurso didático para tornar as aulas de Geografia mais dinâmicas e interativas foram alcançados de modo bastante satisfatório, os resultados puderam ser verificados através da dinâmica e do envolvimento dos alunos durante as aulas, somando-se a análise positiva das atividades desenvolvidas com base nos conteúdos trabalhados.

Dessa forma, esta experiência também se mostra como uma pesquisa que reforça a importância do uso da imagem como ferramenta didática no trabalho com os temas abordados 
na Geografia, e nas diversas áreas do conhecimento. A partir das atividades realizadas foi reforçada a necessidade de estabelecer uma relação cada vez mais estreita entre espaço acadêmico e espaço escolar, objetivando uma parceria colaborativa entre os compõe essas realidades.

A experiência do Estágio Supervisionado II permitiu uma visão ampliada dos processos que transitam no meio escolar: o ensino, a aprendizagem, a didática e o trabalho pedagógico desenvolvido. Destaca-se que, a didática desenvolvida pelo professor de Geografia na sala de aula e as metodologias utilizadas são variáveis que se configuram em diferentes faces do processo de ensino-aprendizagem e, dessa forma, são construídas e reconstruídas para atender as necessidades do público escolar.

Nesse viés, a prática de ensino em Geografia deve considerar diversos fatores, como a faixa etária, as origens do aluno, o seu conhecimento prévio, a realidade em que vive, o comportamento cidadão e suas aspirações de futuro, para que se tenha melhores condições de ensino e de aprendizagem na disciplina. Desse modo, o processo de ensino e aprendizagem desenvolvido na escola não é um processo mensurável que pode ser quantificado, mas sim uma série de variáveis que devem ser trabalhadas pela escola em via da construção do conhecimento.

Ademais, a partir da experiência formativa oportunizada por meio da realização do estágio mostra a importância do professor-pesquisador, tendo em vista que através das experiências de campo podemos observar onde teoria e prática se aproximam e onde se afastam, promovendo reflexões sobre a prática pedagógica desenvolvida em sala de aula, e sobre a busca de estratégias e metodologias que possibilitem conferir significação no processo de construção do conhecimento Geográfico.

\section{REFERÊNCIAS}

BARREIRO, I. M. F.; GEBRAN, R. A. Prática de ensino e estágio supervisionado na formação de professores. São Paulo: Avercamp, 2006.

BARROS, J. D. S.; SILVA, M. F. P.; VÁSQUEZ, S. F. A prática docente mediada pelo estágio supervisionado. Atos de Pesquisa em Educação, Blumenau, v. 6, n. 2, p. 510-520, mai./ago. 2011. Disponível em: https://proxy.furb.br/ojs/index.php/atosdepesquisa/article/view/1661. Acesso em: 20 nov. 2018.

BRITO, J. A. Caminhos e possibilidades para o Ensino de Geografia. Entrelaçando - Revista Eletrônica de Culturas e Educação, v.3, n. 05. jan./abr. 2012. Disponível em: https://www2.ufrb.edu.br/revistaentrelacando/component/phocadownload/category/170?down load=173. Acesso em: 10 nov. 2018. 
FANTIN, M. E.; TAUSCHECK, N. M.; NEVES, D. L. Metodologia do Ensino de Geografia. 2 ed. Curitiba: IBPEX, 2010.

FARINHA, M. J. U.S.; VIEIRA; A. B. Imagens e desenhos do meu bairro: a Geografia no ensino fundamental. Revista de Geografia (Londrina) v. 24, n. 2. p. 105-124, jul./dez. 2015. Disponível em: http://www.uel.br/revistas/uel/index.php/geografia/article/viewFile/20437/19317. Acesso em: 25 nov. 2018.

FERREIRA, E. K.; PÁTARO, C. S. de O. O cinema como recurso didático e pedagógico na educação dos jovens. In: ENCONTRO DE PRODUÇÃO CIENTÍFICA E TECNOLÓGICA, 5., 2010, Campo Mourão. Anais [...]. Campo Mourão: FECILCAM/NUPEM, 2010. n. p. Disponível em: http://www.fecilcam.br/nupem/anais_v_epct/PDF/ciencias_humanas/06_FERREIRA_P\%C3 \%81TARO.pdf. Acesso em 28 nov. 2018.

LIBÂNEO, J. C. Didática. São Paulo: Cortez, 1994. 263 p.

MARTINS, R. E. M. W. TONINI, I. M. A importância do estágio supervisionado em Geografia na construção do saber/fazer docente. Geografia, Ensino \& Pesquisa, Santa Maria, v. 20, n.3, p. 98-106, 2016. Disponível em: https://periodicos.ufsm.br/geografia/article/view/21000. Acesso em 05 dez. 2018.

MORAIS, N. R.; MELO, J. A. B. Discutindo as categorias geográficas no ensino médio a partir de novas metodologias didáticas. Revista de Geografia (UFPE), Recife, v. 32, n. 1, 2015. Disponível em: https://periodicos.ufpe.br/revistas/revistageografia/article/view/229138. Acesso em: 10 dez. 2018.

OLIVEIRA, D. S. et al. O ensino de Geografia e a vivência da equipe do projeto PIBID na Escola Polivalente, Campina Grande-PB. In.: ENCONTRO ESTADUAL DE GEOGRAFIA, 20., 2013, Natal. Anais [...]. Natal: UFRN, 2013. Disponível em: http://docplayer.com.br/76423061-O-ensino-de-geografia-e-a-vivencia-da-equipe-pibid-naescola-polivalente-campina-grande-pb.html. Acesso em: 10 dez. 2018.

PENA, R. F. A. Concentração e desconcentração industrial no Brasil. Brasil Escola. Disponível em: https://brasilescola.uol.com.br/brasil/concentracao-desconcentracaoindustrial-no-brasil.htm. Acesso em: 23 fev. 2019.

PIMENTA, S. G; LIMA, M. S. L. Estágio e docência. 7.ed. São Paulo: Cortez, 2012.

PONTUSCHKA, N. N.; PAGANELli, T. L.; CACETE, N. H. Para ensinar e aprender Geografia. São Paulo: Cortez, 2007.

RIBEIRO. E. N.; LIMA. F. J. Estudo da comunicabilidade das imagens: contribuições para o processo de ensino-aprendizagem na escola inclusiva. Revista Brasileira de Tradução

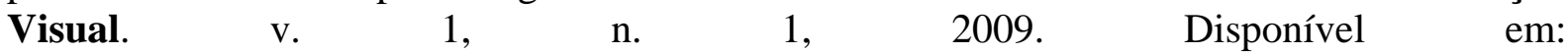
http://www.associadosdainclusao.com.br/rbtv/index.php/principal/article/view/46/55. Acesso em: 15 dez. 2018.

RODRIGUES, M. A. N. Estágio Supervisionado e formação de professor: uma reflexão sobre integração teoria e prática. Tear: Revista de Educação Ciência e Tecnologia, Canoas, v.4, n.2, 
p. 1-13, 2015. Disponível em: https://periodicos.ifrs.edu.br/index.php/tear/article/view/1917. Acesso em: 10 jan. 2019.

SILVA, H. P. B.; BRAGA, E.; SOARES, E. A importância da utilização de imagens no processo de ensino/apredizagem da geografia. Revista Contribuciones a las Ciencias Sociales, abr./jun. 2017. Disponível em: http://www.eumed.net/rev/cccss/2017/02/imagensensino-geografia.html. Acesso em: 16 nov. 2018.

SILVA, J. G.; MELO, J. A. B. Estágio supervisionado em Geografia e atividades lúdicas como proposta para dinamização das aulas. Revista de Geografia (Recife), v. 33. n.. 2, 2016. p. 96-111. Disponível em: https://periodicos.ufpe.br/revistas/revistageografia/article/view/229170. Acesso em: 05 jan. 2019.

TULIO, M. Recursos Didáticos e sua importância para as aulas de geociências no $6^{\circ}$ ano do Ensino Fundamental (colégio Estadual Antonio e Marcos Cavanis/Castro-PR). In: PARANÁ. Secretaria de Estado da Educação. Superintendência de Educação. Os desafios da escola pública paranaense na perspectiva do professor PDE, 2013. Curitiba: SEED/PR., 2013. Disponível http://www.diaadiaeducacao.pr.gov.br/portals/cadernospde/pdebusca/producoes_pde/2013/20 13_uepg_geo_artigo_mariliz_tulio.pdf. Acesso em: 15 jan. 2019.

TV ESCOLA. Origens e influências da Literatura de Cordel. TV ESCOLA, 2015. Disponível em: https://api.tvescola.org.br/tve/post?vlPost=cordel-escola-epoesia\&idPost=9969. Acesso em: 20 nov. 2018.

VITTE, A. C.; SILVEIRA, R. W. D. Considerações sobre os conceitos de natureza, espaço e morfologia em Alexander von Humboldt e a gênese da geografia física moderna. História, Ciências, Saúde - Manguinhos, Rio de Janeiro, v.17, n.3, p. 607-626, jul./set. 2010. Disponível em: http://www.revistas.usp.br/geousp/article/view/74156. Acesso em: 08 jan. 2019.

ZATTA, C. I.; AGUIAR, W. G. O uso de imagens como recurso metodológico para estudar Geografia. Dia a Dia Educação, 2009. Disponível em: http://www.diaadiaeducacao.pr.gov.br/portals/pde/arquivos/2375- .pdf. Acesso em: 17 nov. 2018. 